\title{
Corrigendum: Streptococcus agalactiae clones infecting humans were selected and fixed through the extensive use of tetracycline
}

Violette Da Cunha, Mark R. Davies, Pierre-Emmanuel Douarre, Isabelle Rosinski-Chupin, Immaculada Margarit, Sebastien Spinali, Tim Perkins, Pierre Lechat, Nicolas Dmytruk, Elisabeth Sauvage, Laurence Ma, Benedetta Romi, Magali Tichit, Maria-José Lopez-Sanchez, Stéphane Descorps-Declere, Erika Souche, Carmen Buchrieser, Patrick Trieu-Cuot, Ivan Moszer, Dominique Clermont, Domenico Maione, Christiane Bouchier, David J. McMillan, Julian Parkhill, John L. Telford, Gordan Dougan, Mark J. Walker, The DEVANI Consortium, Matthew T. G. Holden, Claire Poyart \& Philippe Glaser

Nature Communications 5:4544 doi: 10.1038/ncomms5544 (2014); Published 4 Aug 2014; Updated 28 Jan 2015

The original version of this Article contained an error in the spelling of a member of the DEVANI Consortium, Lucilla Baldassarri, which was incorrectly given as Lucilia Baldassari. This has now been corrected in both the PDF and HTML versions of the Article. 